\title{
Sepsis Induces Telomere Shortening: a Potential Mechanism Responsible for Delayed Pathophysiological Events in Sepsis Survivors?
}

\author{
Naara Mendes Oliveira, ${ }^{1}$ Ester CS Rios, ${ }^{1,2}$ Thais Martins de Lima, ${ }^{1}$ Vanessa Jacob Victorino, ${ }^{1}$ \\ Hermes Barbeiro, ${ }^{1}$ Fabiano Pinheiro da Silva, ${ }^{1}$ Csaba Szabo, ${ }^{2}$ and Francisco Garcia Soriano ${ }^{1}$ \\ ${ }^{1}$ Departamento de Clínica Médica, Faculdade de Medicina da Universidade de São Paulo, São Paulo, SP, Brasil; and \\ ${ }^{2}$ Department of Anesthesiology, University of Texas Medical Branch, Galveston, TX, United States of America
}

\begin{abstract}
Sepsis survivors suffer from additional morbidities, including higher risk of readmissions, nervous system disturbances and cognitive dysfunction, and increased mortality, even several years after the initial episode of sepsis. In many ways, the phenotype of sepsis survivors resembles the phenotype associated with accelerated aging. Since telomere shortening is a hallmark of aging, we investigated whether sepsis also leads to telomere shortening. Male balb/c mice were divided into two groups: the control group received $100 \mu \mathrm{l}$ of normal saline intraperitoneally (i.p.) and the sepsis group received $15 \mathrm{mg} / \mathrm{kg}$ of bacterial lipopolysaccharide i.p. After $48 \mathrm{~h}$, animals were euthanized to collect blood, spleen and kidney. The human component of our study utilized blood samples obtained from patients in the trauma department and samples collected $7 \mathrm{~d}$ later in those patients who developed sepsis. Telomere length was measured by quantitative polymerase chain reaction. Since oxidative stress is a known inducer of telomere shortening, thiobarbituric acid-reactive substances and superoxide dismutase activity were analyzed to evaluate oxidative stress burden. Induction of endotoxemia in mice resulted in significant telomere shortening in spleen and kidney. Blood cells from patients who progressed to sepsis also exhibited a statistically significant reduction of telomere length. Endotoxemia in mice also induced an early-onset increase in oxidative stress markers but was not associated with a downregulation of telomerase protein expression. We conclude that endotoxemia and sepsis induce telomere shortening in various tissues and hypothesize that this may contribute to the pathogenesis of the delayed pathophysiological events in sepsis survivors.
\end{abstract}

Online address: http://www.molmed.org

doi: $10.2119 / \mathrm{molmed} .2016 .00225$

\section{INTRODUCTION}

Sepsis is defined as life-threatening organ dysfunction due to a dysregulated host response to infection (1). The host immune response to the pathogenic microorganism results in a complex proinflammatory and coagulant response (2-7). Part of the response during systemic inflammatory response syndrome involves the production of various labile reactive species, including various gaseous mediators as well as reactive oxygen species; these species are known to mediate and amplify some of the pathophysiologic events during the exacerbated inflammatory response. Oxidative stress is one of the best characterized pathophysiological triggers of DNA damage (8-10).

The ends of chromosomes are protected from degradation by repetitive sequences of TTAGGG and associated proteins. This region, called telomere, plays an important

Address correspondence to Francisco Garcia Soriano, Departamento de Clínica Médica, Faculdade de Medicina da Universidade de São Paulo, Avenida Doutor Arnaldo, 455, sala 3189, São Paulo, SP, Brasil, CEP 01246903. Phone: + 5511 30617227; Fax: +55 11 30617072; E-mail: gsoriano@usp.br

Submitted November 15, 2016; Accepted for Publication November 21, 2016;

Published Online (www.molmed.org) December 5, 2016.

HY

Feinstein Institute

for Medical Research Northwell Health"

role in chromosome-chromosome fusions, DNA damage recognition, chromosome replication and nuclear organization (11). In addition, the telomere controls cellular senescence and is involved in the regulation of gene expression (12). The telomeric sequence ensures the annealing of telomerase, an enzyme responsible for complete telomere replication, minimizing progressive telomere shortening during cellular division (13). Telomere shortening depends on initial telomere length in addition to telomerase activity, the expression of which is tissue- and individual-specific $(14,15)$. Importantly, the telomere region is susceptible to damage caused by oxidative stress, among other epigenetic events (16). Telomere shortening is a hallmark and putative causative event in physiological aging $(12,14)$.

Sepsis survivors suffer from additional morbidities, including a higher risk of 
readmissions, as well as nervous system disturbances and cognitive dysfunction, culminating in increased mortality even several years after the initial episode of sepsis $(2,17)$. The mechanisms involved in the delayed consequences of sepsis remain unclear (18).

Because from a clinician's point of view the phenotype of sepsis survivors resembles the phenotype associated with accelerated aging, in this study we evaluated whether sepsis can lead to telomere shortening. The data show that both experimental endotoxemia in mice and sepsis in human patients induce significant telomere shortening in various tissues. We hypothesize that this response may contribute to the pathogenesis of delayed adverse events in sepsis survivors.

\section{MATERIALS AND METHODS}

\section{Animal Studies}

All procedures were performed in accordance with the Guide for the Care and Use of Laboratory Animals published by the US National Institutes of Health. The study protocol was approved by the Research Ethics Committee of the University of São Paulo School of Medicine (Comissão de Ética para Análise de Projetos de Pesquisa do HCFMUSP, http:/ / www.hcnet.usp.br/ adm/dc/cappesq/) (No. 356/11). For all experimental procedures, animals were anesthetized intraperitoneally (i.p.) with a mixture of ketamine $(100 \mathrm{mg} / \mathrm{kg})$ and xylazine $(5 \mathrm{mg} / \mathrm{kg})$. The study was conducted in 8-wk-old male balb/c mice divided into two groups: the control group received $100 \mu \mathrm{l}$ of normal saline $(\mathrm{NaCl}$ $0.9 \%$ ) i.p. and the sepsis group received $15 \mathrm{mg} / \mathrm{kg}$ of lipopolysaccharide (LPS) i.p. After $1 \mathrm{~h}$ or $48 \mathrm{~h}$, the animals were euthanized and blood, spleen and kidney samples were collected.

\section{Human Studies}

The human component of the study was approved by the Human Ethics Committee of the Research Ethics Committee of the University of São Paulo School of Medicine (Comissão de Ética para Análise de Projetos de Pesquisa do HCFMUSP, http:/ /www.hcnet.usp.br / adm/dc/cappesq/) (No. 1207/09), with written consent of all involved. Nine individuals, male and female, born between 1966 and 1993 were included in this study. Blood samples from patients admitted in the trauma department of the Hospital das Clínicas de São Paulo were collected at admission and after $7 \mathrm{~d}$. Patients included in the study were not diagnosed with sepsis at admission, but progressed to sepsis during $7 \mathrm{~d}$ of hospitalization.

\section{Real-time Polymerase Chain Reaction}

Telomere length was measure by quantitative polymerase chain reaction (PCR). Total DNA was extracted from frozen tissues and heparinized blood from mice and humans with DNeasy Blood and Tissue kit (Qiagen) according to the manufacturer's instructions. All experiments were conducted in accordance with guidelines established by the Research Ethics Committee of the University of São Paulo School of Medicine. Real-time PCR was performed on a 7900HT Fast Real-Time PCR System (Applied Biosystems). The relative expression ratio (experimental/control) was calculated based on the $2-[\Delta][\Delta] \mathrm{Ct}$ method (19). For all expression data, we applied $\log _{2}$ to the values.

DNA concentration was determined in a NanoDrop ND-1000 spectrophotometer (NanoDrop Technologies). Real-time PCR experiments were realized using the SYBR Green detection method (Applied Biosystems). The telomere length was determined by measuring the ratio of telomere content and reference sequence (36B4 single copy) according to previously published methods (20). Telomere quantification of human blood was carried out with 20 ng DNA, telomere primer (100 nM forward 5'- GGTTTTTGAGGGTGAGGGTGAGGGTGAGGGTGAGGGT-3' and $900 \mathrm{nM}$ reverse 5'-TCCCGACTATCCCTATCCСТATCCСТATCCCTATCCCTA-3'). For quantification of control gene $36 B 4$, the primer concentrations were $500 \mathrm{nM}$ of CAGCAAGTGGGAA
GGTGTAATCC and CCCATTCTATCA TCAACGGGTACAA (5'-3'). PCR protocol to telomere was $95^{\circ} \mathrm{C}$ for $10 \mathrm{~min}$, followed by 30 cycles of $95^{\circ} \mathrm{C}$ for $15 \mathrm{~s}, 54^{\circ} \mathrm{C}$ for 2 $\mathrm{min}, 72^{\circ} \mathrm{C}$ for $45 \mathrm{~s}$. Reference PCR cycle (36B4) was $95^{\circ} \mathrm{C}$ for $10 \mathrm{~min}$ and 35 cycles of $95^{\circ} \mathrm{C}$ for $15 \mathrm{~s}, 52^{\circ} \mathrm{C}$ for $30 \mathrm{~s}$ and $72^{\circ} \mathrm{C}$ for $30 \mathrm{~s}$. Concentration of telomere and $36 B 4$ primers of mouse was $250 \mathrm{nM}$. The sequences of mouse primers were as follows: telomere 5' CGCTTTGTTTGGG TTTGGGTTTGGGTTTGGGTTTGGGTT $3^{\prime}$ and 5' GGCTTGCCTTACCCTTACC CTTACCCTTACCCTTACCCT 3'; 36B4 5' ACTGGTATCGGACCCGAGAAG 3' and $5^{\prime}$ TCAATGGTGCCTCTGGAGATT

3' (Callicott). Telomere length was normalized to the mean of the control group, which is expressed as a value of $1.0(100 \%)$.

\section{Lipid Peroxidation}

Lipid peroxidation was evaluated by determining the level of thiobarbituric acid-reactive substances (21) by reading the colorimetric final solution at $535 \mathrm{~nm}$ (Tecan Genius). Tissue samples were homogenized in $1.15 \% \mathrm{KCl}(100 \mathrm{mg} / \mathrm{mL})$ and centrifuged at $14,000 \mathrm{~g}$ for $20 \mathrm{~min}$ at $4^{\circ} \mathrm{C}$. Aliquots of tissue homogenates $(100 \mu \mathrm{L}$ each) were then added to $750 \mu \mathrm{L}$ of acetic acid $20 \%, 100 \mu \mathrm{L}$ of sodium dodecyl sulfate (SDS) $8.1 \%, 300 \mu \mathrm{L}$ of water and $750 \mu \mathrm{L}$ of thiobarbituric acid $0.8 \%$. The mixes were incubated at $95^{\circ} \mathrm{C}$ for $60 \mathrm{~min}$ in glass tubes.

\section{Superoxide Dismutase Activity}

Superoxide dismutase activity was measured in hemolyzed erythrocytes (at a ratio of 1:20 in distilled water) as described (22). The diluted samples were incubated with 1M TRIS buffer, pyrogallol $(1.2 \mathrm{mg} / \mathrm{mL})$. Inhibition of pyrogallol oxidation was measured by spectrophotometer (Tecan Genius) at $420 \mathrm{~nm}$.

\section{Western Blotting}

To analyze the expression of telomerase, frozen tissue samples (100 mg) were pulverized in liquid nitrogen. Samples were then homogenized in a nuclear extraction buffer containing 1\% TX-100, 20 mM Tris (pH 8.0), 150 mM 
$\mathrm{NaCl}$ and proteolytic enzyme inhibitors (40 $\mu \mathrm{g} / \mathrm{mL}$ phenylmethylsufonylfluoride and $10 \mu \mathrm{g} / \mathrm{mL}$ pepstatin; Sigma). After centrifugation for $45 \mathrm{~min}$ at $14,000 \mathrm{~g}$, the protein concentration of supernatants was determined by the Bradford method (BioRad). Protein expression was performed using SDS-polyacrylamide gel electrophoresis. Protein extracts $(100 \mu \mathrm{g} / \mathrm{mL})$ were boiled in loading buffer (150 mM Tris- $\mathrm{HCl} \mathrm{pH}$ 6.8, 4\% SDS, $20 \%$ glycerol, $15 \% \beta$-mercaptoethanol and $0.01 \%$ bromophenol blue) and subjected to electrophoresis in $10 \%$ polyacrylamide gel. Following electrophoretic separation, proteins were transferred to Hybond-P membranes (Amersham Pharmacia Biotech). Membranes were blocked with $5 \%$ nonfat dry milk in phosphate-buffered saline for $1 \mathrm{~h}$. Primary antibody against telomerase was incubated at $4^{\circ} \mathrm{C}$ overnight. After washing twice with phosphate-buffered saline plus Tween $20(0.01 \%)$, secondary antibody horseradish peroxidase conjugate was applied at a dilution of 1:20,000 for $1 \mathrm{~h}$. Blots were washed in phosphate-buffered saline-Tween 20 over $30 \mathrm{~min}$ and were incubated in a SuperSignal enhanced chemiluminesence reagents detection kit (Pierce) and exposed to Kodak O-OMAT-AR photographic film. Band intensity of the same original blot was quantified using Image J software (National Institutes of Health).

\section{Statistical Analysis}

Comparisons between individual groups were performed by $t$ test. In the animal study, unpaired $t$ test was used, and in the human study, paired $t$ test was used. All values are expressed as mean \pm standard error of the mean. Values of $P<.05$ were considered significant. The analyses were performed using Sigma Stat Statistical Software, version 3.1.

\section{RESULTS}

\section{Murine Endotoxemia Induces Telomere Shortening in Various Tissues}

In the first set of experiments, we studied the effect of a short period of
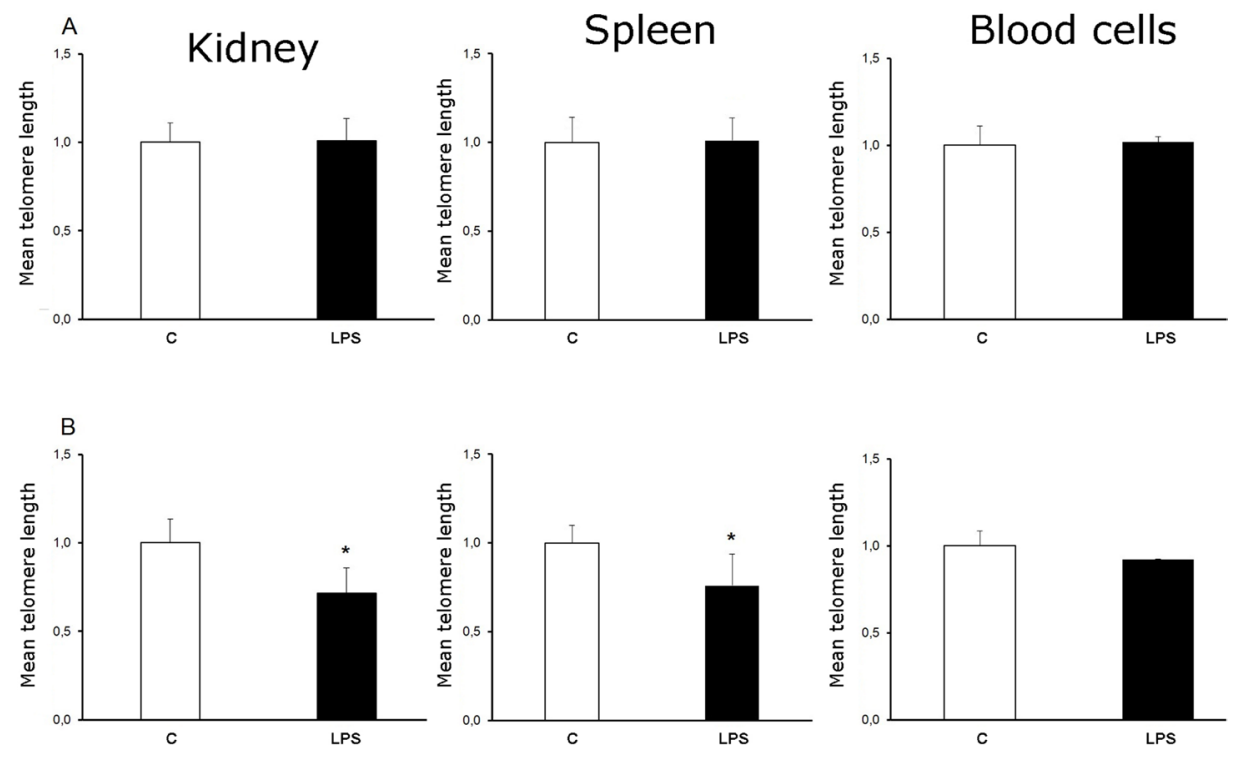

Figure 1. Endotoxemia induces telomere shortening. Analysis of telomere length (A) $1 \mathrm{~h}$ after and (B) $48 \mathrm{~h}$ after endotoxemia induction with LPS (15 mg/kg) in kidney, spleen and peripheral blood samples. Data show mean \pm SEM of $6-8$ animals per group. ${ }^{*} p<.05$.

LPS exposure on telomere size $(1 \mathrm{~h})$. No change in telomere length was detected (Figure 1A). However, at 48 h, LPS induced a significant and dose-dependent telomere shortening in the spleen and liver, and a tendency for decrease was noted in the blood (Figure 1B). None of the animals died in any of the experimental groups; ie, the current model represents a mild to moderate (nonlethal) form of sepsis.

\section{Human Sepsis Induces Telomere Shortening in Blood Samples}

To extend the study to a human population, we analyzed telomere length from blood samples of septic patients at admission and patients who developed sepsis $1 \mathrm{wk}$ later. At $1 \mathrm{wk}$, telomere length was significantly reduced in septic patients (Figure 2).

\section{Endotoxemia Induces Oxidative Stress}

As expected, endotoxemia induced lipid peroxidation in the spleen and kidney as soon as $1 \mathrm{~h}$ after induction of endotoxemia (Figure 3). In parallel, there was also a concomitant increase in tissue antioxidant activity (Figure 4).
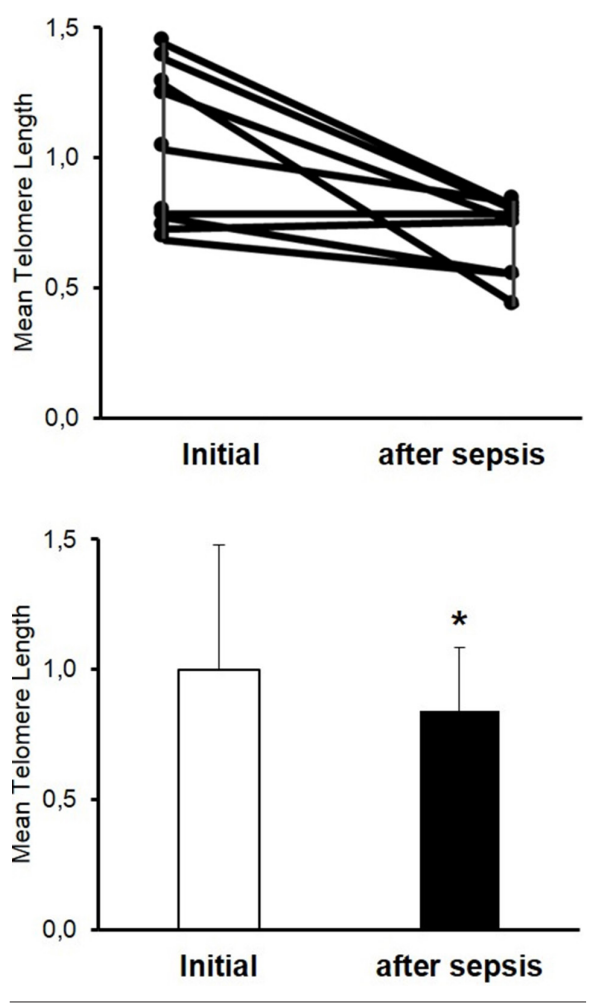

Figure 2. Telomere shortening in patients diagnosed with sepsis. Telomere length of peripheral blood cells from patients at admission and $7 \mathrm{~d}$ after sepsis diagnosis. Data show mean \pm SEM of 9 patients. ${ }^{*} p<.05$. 


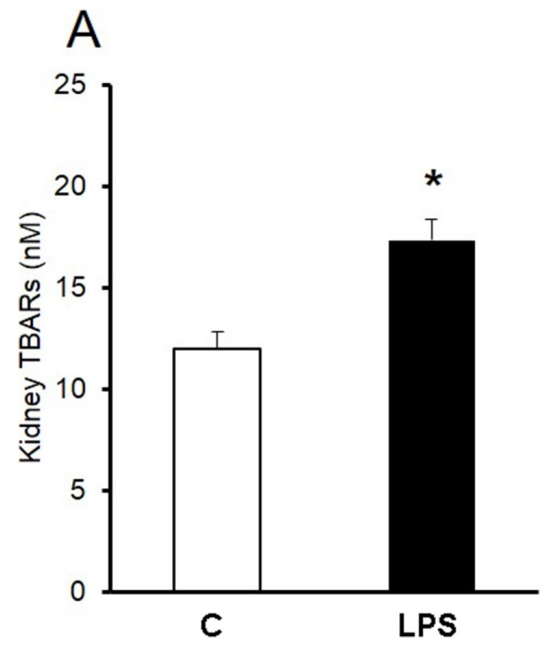

Figure 3. Endotoxemia in mice increases lipid peroxidation in kidney and spleen. Lipid peroxidation is shown in (A) kidney and (B) spleen homogenates from mice $1 \mathrm{~h}$ after LPS $\left(15 \mathrm{mg} / \mathrm{kg}\right.$ ) injection. Data show mean \pm SEM of $6-8$ animals per group. ${ }^{*} p<.05$.

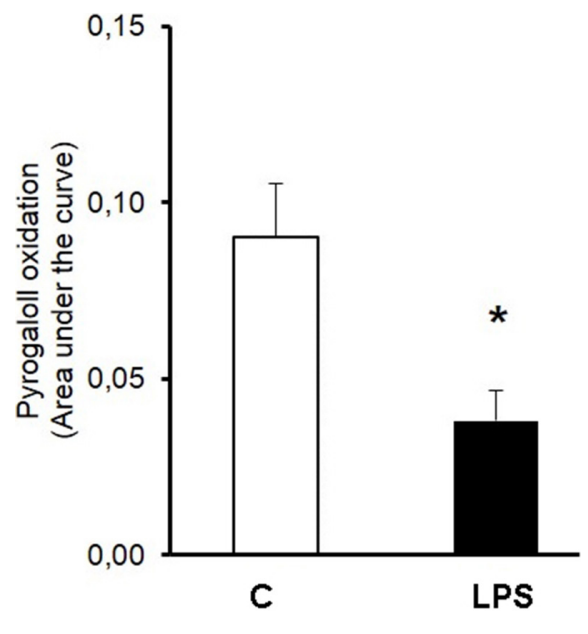

Figure 4. Endotoxemia in mice increases tissue antioxidant activity. Antioxidant activity is shown in erythrocyte samples from mice $1 \mathrm{~h}$ after LPS (15 mg/kg) injection. Data show mean \pm SEM of $6-8$ animals per group. ${ }^{*} p<.05$.

\section{Endotoxemia Does Not Affect Telomerase Expression}

Telomerase expression, as quantified in the kidney, was unaffected by endotoxemia (Figure 5).

\section{DISCUSSION}

In the present study we demonstrated, for the first time to our knowledge, that

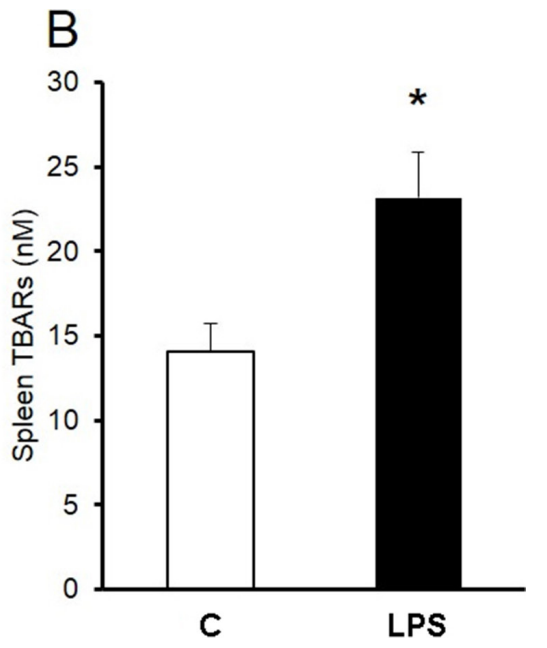

increase in oxidative stress occurs in the analyzed tissues; we hypothesize that this increased oxidative stress may contribute to telomere shortening in sepsis.

Prior studies demonstrated an inverse correlation between oxidative stress and telomere length, which correlated with immune cell senescence and dysfunction (24). Telomere shortening is also associated with the release of several inflammatory factors (25). We hypothesize that in sepsis, oxidative stress, telomere shortening and inflammation may be part of a progressive positive feedback cycle, culminating in immune defects and multiple organ failure, and may contribute to the various post-sepsis pathophysiological events outlined in the Introduction.

In an attempt to maintain tissue homeostasis, oxidative stress is often followed by increases in the expression and/or activity of various enzymes that exert antioxidant effects (26). In our study, SOD activity was found to be increased after LPS; however, this increase is clearly unable to cope with the increased oxidative burden (as evidenced by the detected increases in TBARs).

The imbalance between oxidative stress and the counter regulatory antioxidant system is one of the causes of systemic inflammatory response syndrome $(9,10)$. In our animal study, the enhanced reactive oxygen species production and telomere shortening were more evident in spleen and kidney and less pronounced in the blood, perhaps due to the fact that circulating cells with pronounced DNA damage may undergo apoptosis and necrosis and therefore are not included in the collected material used to quantify telomere length. However, in the human component of our study, we only had access to blood samples (where significant telomere shortening was noted). It is conceivable (and remains to be tested in future studies) that in parenchymal tissues of septic patients, telomere shortening may be more pronounced than that detected in blood samples.

The exact mechanisms responsible for telomere shortening during sepsis remain to be characterized in future 
studies. Our data indicate that earlyonset downregulation of telomerase is not responsible for the observed change in telomere length, although it is conceivable (and remains to be tested) that telomerase expression may be affected by sepsis at later time points and/ or may exhibit tissue heterogeneity post-sepsis.

The long-term complications after sepsis affect the nervous system and several organs, increasing morbidity, decreasing the quality of life and increasing mortality for an extended period (years) after the initial septic period $(18,27)$. We hypothesize that telomere shortening (which is typically considered a progressive and irreversible process) contributes to a phenomenon of "accelerated aging" in post-sepsis patients. However, further studies are needed to confirm and extend these observations. One of the key questions is whether the telomere shortening observed in our study at relatively early time points ( $48 \mathrm{~h}$ in the rodent study and $7 \mathrm{~d}$ in the human study) will continue to occur at an accelerated rate at later time points in the post-sepsis period; another question is whether pharmacological or genetic modulation of this process (prevention or reversal of telomere shortening) will improve the various post-sepsis pathophysiological events.

Although to our knowledge this is the first report to directly link sepsis to telomere shortening, there is a limited number of studies that are relevant for the current report, as they indirectly support our observations. First, Kim et al. recently reported telomere shortening in pulmonary endothelial cells exposed to LPS in vitro (28). In addition, in mice with shorter telomeres (telomerasedeficient mice), LPS induces a more severe proinflammatory response in the microglia (29). Third, in diabetic patients, there is a negative correlation between the degree of endotoxemia and the length of telomeres in circulating leukocytes (30). Finally, in hemodialysis patients (a patient population frequently characterized by septic episodes and/ or systemic inflammatory response), telomere shortening has been reported in circulating leukocytes (31).

In addition to the existing interest in therapeutic approaches for sepsis (where therapy remains supportive and no specific treatments have been identified, even after decades of intensive research), there is also an increasing interest in approaches to improve the health of sepsis survivors $(27,32)$. The current study, by identifying telomere shortening as a potential contributing factor, may open the way for identification of future therapeutic approaches aimed at counteracting this problem.

\section{CONCLUSION}

The present study identified the phenomenon of telomere shortening in experimental sepsis and in septic patients. The telomere participates in regulation of metabolism and is fundamental for tissue regeneration. We hypothesize that protection against telomere shortening may beneficially affect the outcome of sepsis and sepsis-associated organ dysfunction.

\section{ACKNOWLEDGMENTS}

We thank the Fundação de Amparo à Pesquisa do Estado de São Paulo for financial support. CS is supported by a grant from the National Institutes of Health (R01GM107846).

\section{DISCLOSURE}

The authors declare that they have no competing interests as defined by Molecular Medicine, or other interests that might be perceived to influence the results and discussion reported in this paper.

\section{REFERENCES}

1. Singer M, et al. (2016) The third international consensus definitions for sepsis and septic shock (Sepsis-3). JAMA. 315:801-10.

2. Bohuslav J, et al. (1998) Regulation of an essential innate immune response by the p50 subunit of NF-kappaB. J. Clin. Invest. 102:1645-52.

3. Darville T, Giroir B, Jacobs R. (1993) The systemic inflammatory response syndrome (SIRS): Immunology and potential immunotherapy. Infection. 21:279-89.

4. Fry DE, Pearlstein L, Fulton RL, Polk HC. (1980) Multiple system organ failure: the role of uncontrolled infection. Arch. Surg. 115:136-40.
5. Deitch EA. (1992) Multiple organ failure: pathophysiology and potential future therapy. Ann. Surg. 216:117.

6. Salvo I, et al. (1995) The Italian SEPSIS study: preliminary results on the incidence and evolution of SIRS, sepsis, severe sepsis and septic shock. Int. Care Med. 21:S244-49.

7. Brun-Buisson C, et al. (1995) Incidence, risk factors, and outcome of severe sepsis and septic shock in adults. (A multicenter prospective study in intensive care units. French ICU Group for Severe Sepsis.) JAMA. 274:968-74.

8. Kaisho T, Akira S. (2001) Dendritic-cell function in toll-like receptor and MyD88-knockout mice. Trends Immunol. 22:78-83.

9. Galley HF. (2011) Oxidative stress and mitochondrial dysfunction in sepsis. Br. J. Anaesth. 107:57-64.

10. Droge W. (2002) Free radicals in the physiological control of cell function. Physiol. Rev. 82:47-95.

11. de Lange T, et al. (1990) Structure and variability of human chromosome ends. Mol. Cell. Biol. 10:518-27.

12. Harley CB, Futcher AB, Greider CW. (1990) Telomeres shorten during ageing of human fibroblasts. Nature. 345:458-60.

13. Cong YS, Wright WE, Shay JW. (2002) Human telomerase and its regulation. Microbiol. Mol. Biol. Rev. 66:407-25.

14. Balasubramanyam M, Adaikalakoteswari A, Monickaraj SF, Mohan V. (2007) Telomere shortening and metabolic/vascular diseases. Indian J. Med. Res. 125:441-50.

15. Zimmermann S, et al. (2004) Effects of telomerase modulation in human hematopoietic progenitor cells. Stem Cells. 22:741-49.

16. Houben JM, Moonen HJ, van Schooten FJ, Hageman GJ. (2008) Telomere length assessment: biomarker of chronic oxidative stress? Free Radic. Biol. Med. 44:235-46.

17. Hall MJ, Williams SN, DeFrances CJ, Golosinskiy A. (2011) Inpatient care for septicemia or sepsis: challenge for patients and hospitals. NCHS Data Brief. 62:1-8.

18. Benjamin CF, Hogaboam CM, Kunkel SL. (2004) The chronic consequences of severe sepsis. J. Leukoc. Biol. 75:408-12.

19. Livak KJ, Schmittgen T (2001) Analysis of relative gene expression data using real-time quantitative PCR and the 2(-Delta Delta C(T)) Method. Methods. 25:402-08.

20. Cawthona RM. (2002) Telomere measurement by quantitative PCR. Nucleic Acids Res. 30:e47.

21. Devasagayam TP, Boloor KK, Ramasarma T. (2003) Methods for estimating lipid peroxidation: an analysis of merits and demerits. Indian J. Biochem. Biophys. 40:300-08.

22. Marklund S, Marklund G. (1974) Involvement of the superoxide anion radical in the autoxidation of pyrogallol and a convenient assay for superoxide dismutase. Eur. J. Biochem. 47:469-74.

23. Salvemini D, Cuzzocrea S. (2002) Oxidative stress in septic shock and disseminated intravascular coagulation. Free Radic. Biol. Med. 33:1173-85. 
24. Fritsch RD, et al. (2006) Abnormal differentiation of memory $\mathrm{T}$ cells in systemic lupus erythematosus. Arth. Rheum. 54:2184-97.

25. Weng NP. (2008) Telomere and adaptive immunity. Mech. Ageing Dev. 129:60-66.

26. Ortolani O, et al. (2000) The effect of glutathione and $\mathrm{N}$-acetylcysteine on lipoperoxidative damage in patients with early septic shock. Am. J. Res. Crit. Care Med. 161:1907-11.

27. Yende S, Iwashyna TJ, Angus DC. (2014) Interplay between sepsis and chronic health. Trends Mol. Med. 20:234-38.

28. Kim CO, Huh AJ, Han SH, Kim JM. (2012) Analysis of cellular senescence induced by lipopolysaccharide in pulmonary alveolar epithelial cells. Arch. Gerontol. Geriatr. 54:e35-41.

29. Raj DD, et al. (2015) Enhanced microglial proinflammatory response to lipopolysaccharide correlates with brain infiltration and blood-brain barrier dysregulation in a mouse model of telomere shortening. Aging Cell. 14:1003-13.

30. Masi S, et al. (2014) Association between short leukocyte telomere length, endotoxemia, and severe periodontitis in people with diabetes: a cross-sectional survey. Diab. Care. 37:1140-47.

31. Ramírez R, et al. (2005) Stress-induced premature senescence in mononuclear cells from patients on long-term hemodialysis. Am. J Kidney Dis. 45:353-59.

32. Winters BD, et al. (2010) Long-term mortality and quality of life in sepsis: a systematic review. Crit. Care Med. 38:1276-83.

Cite this article as: Oliveira NM, et al. (2016) Sepsis induces telomere shortening: a potential mechanism responsible for delayed pathophysiological events in sepsis survivors? Mol. Med. 22:886-91. 